\title{
UMA HERMENÊUTICA DO MAL NA LÓGICA DA FILOSOFIA DE ERIC WEIL
}

\author{
Daniel Benevides Soares ${ }^{1}$ \\ Universidade Federal do Ceará (UFC) \\ (D) https://orcid.org/0000-0001-7275-9217
}

\section{RESUMO:}

Entendendo a violência como a negação do sentido e da razão, bem como a recusa daquilo que compõe a essência do mundo do homem que vive em uma determinada atitude, nosso objetivo no presente trabalho é analisar esse conceito na Lógica da Filosofia de Eric Weil, que apresenta o conjunto dos discursos filosóficos no seu itinerário na forma de categorias, nos detendo naquelas nas quais a violência aparece na forma de mal. Tenciona-se tratar do mal na sua especificidade conforme ele é apresentado pelo autor nas categorias selecionadas, constituindo assim um panorama segundo as variadas possibilidades discursivas. Levamos em conta para isso tanto a sucessão das várias categorias bem como a relação das mesmas com as suas respectivas atitudes. Finalmente, procuramos entender o mal não como um falso problema, mas como uma dificuldade real que se apresenta para a elaboração de um sentido para o mundo do homem.

PALAVRAS-CHAVE: Mal; Eric Weil; Lógica da Filosofia.

\section{A HERMENEUTICS OF THE EVIL IN THE ERIC WEIL'S LOGIC OF THE PHILOSOPHY}

\begin{abstract}
:
Understanding violence as the negation of sense and reason, and the refusal of what makes up the essence of the world of the man who lives in a determined attitude, the aim of this paper is to analyze this concept in Eric Weil's Logical of the Philosophy, which presents the ensemble of the philosophical discourses on your itinerary as categories. We will give attention to those in which violence appears as evil. We will treat the evil in their own characteristics as it is presented by the author in the selected categories, thus forming an overview according to various discursive possibilities. We take into account both the succession of the various

${ }^{1}$ Doutorando em Filosofia na Universidade Federal do Ceará (UFC), Ceará - Brasil. Bolsista CAPES. E-mail: benevides.soares@gmail.com
\end{abstract}


categories as well as the relationship of these categories with their attitudes. Finally, we try to understand the evil not as a false problem, but as a real difficulty to the development of a sense to the world of man.

KEYWORDS: Evil; Eric Weil; Logic of the Philosophy.

\section{Violência e Mal na Lógica da Filosofia}

Principal obra de Weil, a Lógica da Filosofia é o esforço para a compreensão sensata do agir humano em sua dimensão teórica e prática (CAMARGO, 2014, p. 42). É importante explicitar para o propósito desse trabalho que a Lógica da Filosofia desenvolve uma teoria do Ser apenas enquanto ele se mostra no discurso. Trata-se de uma 'lógica dos discursos humanos' ${ }^{2}$ que compreende a realidade humana na medida em que ela quer se compreender. Tal empreitada não é, portanto, ontológica em sentido estrito, mas uma lógica dos discursos na sua unidade, um logos realizado na sua historicidade. Enquanto encontra-se presente historicamente, portanto, esse logos se articula em uma unidade com o fato, pois o fato se reconhece enquanto sensato no logos, e o logos se sabe presente historicamente no fato. Desta feita destacamos dois pontos que nos serão importantes no decorrer da presente exposição: primeiro, a coexistência entre razão e violência - pois a violência será a chave de leitura para compreendermos o mal em determinadas categorias da Lógica da Filosofia - e em segundo lugar, a relação existente entre categoria e atitude ${ }^{3}$. O primeiro desses aspectos que destacamos, deverá ser, no momento, guardado para que o retomemos em breve, quando iniciarmos propriamente a compreensão do mal como violência. Passemos, de imediato, a investigar a relação entre categoria e atitude no trabalho mais famoso de Weil.

A Lógica da Filosofia é composta por 18 categorias e atitudes. As categorias representam as possibilidades do discurso filosófico e nas atitudes encontramos possibilidades reais, de modo que, ao passarmos pelos momentos lógicos descritos nas categorias, descobrimos as atitudes dos homens que vivem segundo aquilo que constitui o essencial e os conceitos centrais que organizam respostas em relação ao mundo e aos próprios indivíduos que nele vivem (CANIVEZ, 1999, p.32). A sequência das

\footnotetext{
${ }^{2}$ Não se trata aqui de uma lógica orientada pelo princípio da não contradição. Os discursos filosóficos que se seguem conforme expostos na principal obra de Weil não são contraditórios em si mesmos, mas se contradizem entre si nas suas respostas e soluções. Tampouco, deve-se identificar essa lógica com aquela concernente ao discurso científico (COSTESKI, 2009, p. 205).

${ }^{3}$ A esse respeito, conferir COSTESKI, 2009, p. 205-206.
} 
categorias obedece a um ordenamento lógico e não histórico ${ }^{4}$. Ao homem é dada a opção de permanecer na atitude que lhe parece natural, sem compreender aquilo que ele vivencia. No caso em que o indivíduo opta por se compreender por meio de um discurso que capte aquilo que constitui o que lhe é essencial, têm lugar as atitudes puras ou irredutiveis, tomadas então como categorias. Estas, por sua vez, são o conceito no seio do qual se dá a organização e o sentido daquilo que os homens executam e que no itinerário da Lógica da Filosofia aparece como uma categoria do discurso e não como uma categoria metafísica": "Ela é, pois, a categoria de uma atitude pura e irredutível, cuja pureza e irredutibilidade lhe vêm do discurso que ela produz" (PERINE, 1987, p. 137).

A categoria determina a atitude no que concerne a sua pureza e irredutibilidade, mas, historicamente, a primeira é posterior a segunda. Temos, então, uma atitude vivida, que é seguida por uma consciência categorial. Dito isso, uma lógica da filosofia se incumbe de - abrindo para o homem uma compreensão que por sua vez tem por instrumento uma idéia da sucessão dos discursos coerentes - mostrar como o discurso pode se formar na história partindo de uma atitude primeira da qual o homem não tem por obrigação se retirar ${ }^{6}$. Assim, após constatarmos que o discurso nasce da história, podemos em seguida compreender que sua origem está no reino da violência (PERINE, 1987, p. 139). Podemos também tornar esse ponto mais claro ao observarmos que a passagem de uma atitude para outra ${ }^{7}$ na sua sucessão histórica é um evento marcado pelo descontentamento do indivíduo, sendo por isso uma mudança que é essencialmente violenta (PERINE, 1987, p. 140). Como essa mudança segue como ato livre e se faz enquanto uma ruptura que expressa um descontentamento com uma atitude anterior que não é mais doadora de sentido, é possível falar de uma circularidade entre as categorias e atitudes: embora insuficiente, o discurso avito é retomado por uma nova forma de vida enquanto ferramenta de

\footnotetext{
${ }^{4}$ Conferir CAMARGO, 2014, p. 46. As categorias são as seguintes, conforme aparecem na Lógica da Filosofia: verdade, não sentido, verdadeiro e falso, certeza, discussão, objeto, eu, Deus, condição, consciência, inteligência, personalidade, absoluto, obra, finito, ação, sentido e sabedoria. Para nosso propósito, nos deteremos nas categorias da discussão, objeto, Deus, consciência e obra.

5 Conferir PERINE, 1987, p 137.

6 Conferir PERINE, 1987, p 137-138.

7 Quando tratamos da sucessão das categorias é importante ressaltar aquele que Weil denomina como um fenômeno fundamental na história do pensamento: o conceito de retomada. Captação do novo em uma linguagem antiga, a retomada ocorre quando um determinado mundo anterior e que já se encontra abrigado no seu próprio discurso é recusado por um mundo nascente. Essa nova atitude ainda não se constituiu como pura porque ainda não elaborou seu linguajar próprio, de modo que no esforço para apreender o essencial do seu mundo, ela recorre ao aparato discursivo de uma categoria que a precede, o que acaba promovendo deformações no discurso do qual ela se serve (WEIL, 2012, p. 122)
} 
compreensão ${ }^{8}$ Dessa maneira chega para nós um dos pontos da relação que a violência mantém com a razão, com o que passamos a nos ocupar a partir de agora.

Problema fundamental da filosofia para Weil, a violência ${ }^{9}$, enquanto oposição a razão, encontra-se presente na Lógica da Filosofia, sempre como um caminho que o homem é capaz de tomar (WEIL, 2012, p. 87). É importante ressaltar que violência em Weil não se restringe a um dado físico, uma agressão, um assassinato, um crime. Ela apresenta os limites da razão, constituindo-se como seu outro, como seu negativo, por ser a recusa e rejeição do universal e do sentido (PERINE, 1987, p. 124). A violência mantém uma relação de mútua implicação com a razão, pois a fonte do discurso é o mundo da violência no qual ele se origina e que ele reflete. Como o propósito do discurso é a progressiva eliminação da violência que se encontra no mundo do qual ele brota, observamos na historicidade a sucessão dos vários discursos que buscam dar conta do problema seminal da violência (CAMARGO, 2014, p. 46). Por outro lado, embora a violência seja a negação de tudo aquilo que constitui o sentido para o homem, ela mesma só é reconhecida por aquilo que a nega, a razão (PERINE, 2004, p. 72). Dito isso, recordemos que uma categoria representa o que constitui o sentido para o indivíduo que vive sob uma determinada atitude. Como a violência é também negação do sentido, o mal, na Lógica da Filosofia, também pode ser pensado como violência. Privilegiamos nesse trabalho as categorias nas quais existe uma menção direta ao mal na exposição dos seus respectivos discursos. Com base nessa diretriz, trataremos das categorias da discussão, do objeto, de Deus, da consciência e da obra.

\section{O Mal nos Discursos Filosóficos}

O mal na discussão está na contradição que a categoria quer eliminar. Isso porque o propósito que a discussão busca alcançar é libertar o homem dos acidentes da particularidade; ao fazer dele razoável, ela o encaminha para a virtude. Identificando saber com ação virtuosa, ou seja, com o Bem, a discussão põe nos domínios do mal a paixão que não é percebida como uma parte substancial do indivíduo, sendo essencialmente algo de que a conduta virtuosa tem o poder de libertar:

Ora, para o homem da discussão, ela não passa de um acidente. Basta que ele saiba o que ele é para que seu ser se desvencilhe desse peso morto que lhe é tão pouco natural quanto os grilhões o são para o prisioneiro. Uma obrigação poderia existir para um ser composto, mas o indivíduo razoável seguirá a virtude tão logo saiba o que ela é; ele não peca porque uma

\footnotetext{
${ }^{8}$ Conferir CAMARGO, 2014, p. 47.

${ }^{9}$ Conferir CANIVEZ, 1999, p. 38.
} 
força má ou maligna o empurra para o mal - o mal é apenas a ausência do Bem -, ele peca por ignorância. O homem, o verdadeiro homem, não é apenas bom; é virtuoso. Como iria ele para o mal constituído pela contradição? (WEIL, 2012, p. 195-196).

Tendo por causa a ignorância e a negligência e não a malignidade de alguma entidade, o mal é entendido enquanto ausência de Bem. Além disso, no panorama representado pela discussão, o indivíduo verdadeiramente bom e virtuoso, ao deparar-se com o Bem, não optaria pelo mal assentado na contradição, na conduta incoerente. No discurso que apresenta, a categoria situa o mal no âmbito da adequação, posto que é possível superar o acidente da particularidade por meio do conhecimento do que é adequado, o que torna o homem verdadeiramente bom, tão logo esse indivíduo razoável saiba o que é a virtude. É interessante atentar para essa definição de indivíduo razoável. Incorre-se, na discussão, em uma interpretação do mal como sendo representado pela contradição, pela ignorância. Não se admite aqui que o mal se dê por uma escolha, pois a preocupação com a liberdade não é parte do essencial dessa categoria, isso porque o homem da discussão não se dá conta de que não é integralmente razão: "Ele se vê como razão rumando para si mesma, e o fato essencial para nós não lhe é visível, a saber, que ele não é razão, precisamente porque ele é apenas razão caminhante." (WEIL, 2012, p. 197).

Não é parte do essencial dessa categoria que o homem possa, conhecendo o que seja a virtude, querer realizar o mal. Se ele age em contradição com a virtude, ele apenas o faz enquanto não sabe o que é ser virtuoso, ou seja, de modo inadvertido. Dessa feita, a discussão se entende como a não-violência na forma do discurso cuja diretriz essencial é a nãocontradição, pois a violência passional exterior ao discurso é percebida como aquilo que aparece na forma de contrariedade para a necessidade lógica; violência, portanto, é a não-verdade que impede o aparecimento do verdadeiro. É importante chamar atenção para algo que passa despercebido para o homem que vive a atitude dessa categoria: que a violência na discussão só é interrompida durante a duração do diálogo. Além disso, assim como a discussão não admite que se queira praticar livremente o mal, a categoria possui apenas uma conceitualização em nível formal e negativo do que seja a violência, de modo que não faz entra na composição do seu essencial aquilo que está na ordem de um fato: o homem pode simplesmente recusar a discussão, abandonando o outro ao seu próprio discurso (CAILLOIS, 1984, p. 215).

$\mathrm{Na}$ categoria do objeto o entendimento do mal guarda semelhanças com o que ocorre na discussão, pois ele não deixa de ser entendido também como contradição. Contudo, compreendendo o mal como particularidade, no objeto a diferença é que o homem, tido como razoável, é percebido como não sendo inteiramente razão: 


\begin{abstract}
O bom senso respondeu a discussão: não basta que o homem veja o Bem, pois ele não é essencialmente razoável; por mais que se convença de que a particularidade é a contradição e o mal, ele continua sendo o que ele é, o que significa que ele é determinado. Conforme essa visão, o essencial é a paixão, o

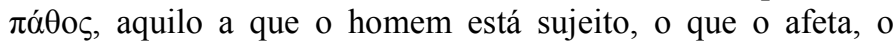
arrasta, o impele - a matéria nele; ele é razoável, mas ele é somente também razoável. Tomada isoladamente, a humanidade é razoável, não o indivíduo que pode sê-lo, assim como o gênero cão se caracteriza pela fidelidade ao dono, sem que se possa dizer que essa qualidade se encontra em todos os cães. (WEIL, 2012, p. 213).
\end{abstract}

Essa forma de encarar o homem, enquanto ser que não é razão por inteiro, permite situar o problema do mal no contexto de uma relação com a liberdade. O componente da particularidade, as paixões, podem interferir na razão, suplantando-a. Reconhece-se então que o indivíduo pode acabar não agindo razoavelmente, por conta de sua própria constituição: "O homem comum situa-se entre o animal, que está na natureza, e a razão, que está além da natureza" (WEIL, 2012, p. 214).

Percebe-se o mal na categoria Deus na postura daquele cujo sentimento não se encontra em consonância com a divindade. Dessa forma, não se trata aqui de uma entidade pessoal, metafísica ou dotada de um estatuto ontológico; não se deve procurá-lo em algo para além do sentimento humano: "O Mal não é um ser independente, ele está no ser que se crê independente - não quanto a sua existência, mas quanto ao seu sentimento -, que não sente junto com Deus" (WEIL, 2012, p. 283). De maneira semelhante a categoria do objeto, o mal reside na particularidade, mas não em uma passionalidade que o homem arrasta de sua herança animal, ele é o particular que se sente vinculado apenas ao próprio sentimento e que se sente, por outro lado, apartado de Deus, em oposição aquilo que a categoria toma como essencial: o estado de unidade com Deus.

Quando pensamos nesse desengano como um equívoco, podemos tomar o mal aqui enquanto conflito. Dessa forma, vemos a atitude Deus ainda não tornada pura, ou seja, desprovida de um discurso próprio para a tradução do seu essencial, o que lhe obriga a tomar emprestado, por meio da retomada, a fala da discussão para tratar do problema do mal. A contradição conflituosa nesse caso não está entre o homem e Deus, ou melhor, entre aquele que entende que o essencial é unir-se a Deus e a própria divindidade; o conflito situa-se apenas na situação daquele que entra em contradição com essa união: "Não existe, portanto, conflito entre Deus e o homem que se dá a Deus, eles conversam como amigos. Mas existe a discussão entre Deus e o homem que se retém e que não consegue se dar inteiramente" (WEIL, 2012, p. 283). 
A retomada da discussão surge como reveladora do mal porque, por meio dela, seria possível o nascimento de um acordo que conduzisse ao sentimento de cisão do homem em relação a Deus. Essa não é, no que tange ao mal, a única possibilidade de retomada de uma categoria anterior pela categoria Deus. Ao levarmos em conta a contradição como mal na retomada da discussão, é possível também tomar a obstinação do sentimento particular no seu isolamento em relação a Deus como uma retomada do objeto. Isso porque esse isolamento, que gera a contradição na forma da separação de Deus de uma parcela que lhe pertence, o homem, se dá via sentimento particular.

Em outras palavras, à retomada da discussão pode corresponder a do objeto e a da ideia de ciência objetiva: visto que não se institui esse diálogo no qual o coração compreende o coração, que a ação do discurso do crente não penetra a incompreensão do outro que permanece preso na tradição, que Deus não reabsorve aquela parte de Si mesmo que adentrou a finitude, a solução das contradições deve ser encontrada na observação da realidade divina, pois só ela proporcionará a solução. A vida é o que é, e Deus está presente a Si mesmo. É preciso apreender um e outro em sua essência: realizada essa apreensão, o homem poderá escolher com conhecimento de causa evitando o acordo fortuito que poderia ser o acordo sobre o Mal. (WEIL, 2012, p. 284).

Quando se chega à categoria da consciência, o mal é entendido como se tratando das inclinações naturais e do sentimento passional que atrapalham na autodeterminação moral do indivíduo, o que salienta o papel que a liberdade desempenha nessa forma de compreender o mal que acomete o homem. "Ele é sujeito da condição, e a luta contra a natureza é a luta com ele próprio nele próprio, onde ele sempre encontra a natureza e, com ela, o mal" (WEIL, 2012, p. 346). A presença fundamental da liberdade evidencia que o mal se desenrola para a categoria da consciência tendo como pano de fundo o contexto da moralidade, palco no qual se desenrola o movimento reflexivo da consciência. Aqui é essencial ressaltar aquilo que constitui as condições do agir do sujeito moral e que por sua vez não devem estar no cálculo da ação moral: as paixões.

Essencialmente, a consciência se volta, portanto, para si mesma: é preciso agir por respeito à lei moral, porque é somente nessa ação que o homem pode esperar ser ele próprio. É preciso subjugar, visto que é impossível extirpar, as determinações interiores, as paixões: elas são as condições naturais da ação no mundo, mas precisamente porque são necessárias, permanecem fora da moral e não devem entrar na decisão. (WEIL, 2012, p. 347). 
Passemos agora para o momento da Lógica da Filosofia que apresenta a refutação consciente da razão: a obra. Situada fora da ordem da busca pela compreensão, a obra compõe em conjunto com o finito e a ação a tríade que assinala a primeira ruptura definitiva no discurso lógico da razão. Essa quebra irreparável se caracteriza pela preocupação central com o agir, e é tratada por Weil como a categoria que tenta reconhecer aquela atitude segundo a qual vive o homem violento ${ }^{10}$. Para a obra, o que está em jogo é apenas sua auto-realização ininterrupta, de modo que na sua atitude não se vivencia uma preocupação com o verdadeiro e o falso ou que almeje um universal (CANIVEZ, 1999, p.63). Nesse sentido, é aqui se verifica uma fratura em relação não apenas ao essencial de um mundo vetusto, mas mesmo uma refutação consciente da razão por meio da violência. A preocupação então passa a ser não com um sentido implícito, mas apenas conferir ao mundo uma forma que espelhe a própria obra ${ }^{11}$.

Segundo Caillois (1984, p. 215) a obra nos coloca diante da violência pura em exercício. Ainda segundo o autor (1984, p. 214), a violência pura apresenta a transgressão consciente da lei moral, do universal e da razão. Considerada violência pela violência, essa barbárie voluntária pode ser subdividida em duas formas. A primeira delas é a violência do tédio, obra de um indivíduo ou de um pequeno grupo, tornada banal em um mundo dessacralizado. A segunda é a forma totalitária, que por sua vez pede o sacrifício da individualidade é requer a existência de um Estado, um mestre, um partido; um Estado ideocrático, por exemplo, está apto a atender as necessidades dessa forma. Dito isso, podemos então começar a localizar a obra no que tange ao problema do mal. Para isso, será necessário recorrer ao pensamento weiliano para além da Lógica da Filosofia, de modo que possamos entender o conceito de uma vontade diabólica para tratar do mal como violência pura na categoria da obra.

Weil declara que, em oposição a Kant, é possível que a vontade humana se faça diabólica (1982, p. 273). Essa vontade diabólica que Weil julga possível, em contraposição ao filósofo de Königsberg, equivale aos móveis da ação moral discutidos no livro A Religião nos Limites da Simples Razão. Nesse trabalho, Kant defende que a diferença entre uma boa ou má conduta moral não se encontra nos móveis desse ato, mas em qual dos móbiles está subordinado ao outro com relação a forma da máxima moral que é acolhida. Disso resulta que o homem acaba por inverter a ordem dos móbiles morais, subordinando como condição para uma conduta moral as leis da moralidade ao amor de si e as suas inclinações (KANT, p. 42). Deste modo, para o filósofo de Königsberg, o homem não pode ser tomado enquanto uma natureza intrínseca e estritamente inserida na maldade, pois não acolhe o puro mal como princípio subjetivo da sua máxima moral; ele

\footnotetext{
${ }^{10}$ Conferir PERINE, 1987, p 150.

${ }^{11}$ Conferir CANIVEZ, 1999, p.65.
} 
deve ser considerado perverso, posto que ele subverte a máxima moral ao amor de $\mathrm{si}^{12}$. Esse mal oriundo de uma vontade puramente diabólica que Kant julga inacessível para as capacidades humanas, em Weil, aparece na forma de uma violência pura, recusa e rejeição da razão, imanada de um sentimento e que é descortinada por meio da categoria da obra, na qual aparece na Lógica da Filosofia aquilo que para o discurso se mostra como impensável: a negação da conduta razoável com conhecimento de causa. Essa negação, contudo, não se dará no plano do próprio discurso - e é por isso que a razão considera como um escândalo a possibilidade de que ela possa ser negada -, mas sim no âmbito do agir, da atividade pura. Chegamos aqui no plano específico da obra.

Nessa categoria se apresenta a negação do discurso razoável por meio da violência pura que, como vimos, se manifesta tanto motivada pelo tédio quanto pela sua forma total. Em ambas as erupções da violência pura, é possível falar de um sentimento que as motiva: a vontade má. Contudo, essa volição se distingue de uma para a outra. O tédio pode ser entendido aqui como aquilo que motiva a fuga do indivíduo por meio de uma violência que afirma um sentimento que, por sua vez, é a exteriorização da particularidade do indivíduo, o qual, insatisfeito com o contentamento razoável, se sente logrado pela razão ${ }^{13}$, optando, então, por deliberada e livremente rejeitá-la. Se esse modo de pensar o tédio como algo de que se busca escapar pelo emprego de um agir que rejeita momentaneamente a razão se diferencia, por exemplo, do tratamento do tema visto em outros pensadores $^{14}$, o que nos interessa sobremaneira aqui é esse momento de repúdio da conduta razoável. Isso porque no tédio ocorre uma rejeição momentânea da razão, o que se diferencia da sua completa recusa, que é o que acontece na a violência total. Nesse caso, o sentimento que aparece é o sentimento da obra, que refuta o discurso por meio do fato, da pura atividade $^{15}$. "A obra não é o meio de satisfazer um desejo que tem seu lugar no mundo, e o homem da obra não tem desejos que ele queira satisfazer: ele não deseja, ele faz" (WEIL, 2012, p. 501). O sentimento desse homem é particularidade oposta ao universal. Contudo, não se trata de um sentimento propriamente do indivíduo, já que a particularidade se dissolve na realização contínua de um projeto, e sim de um sentimento da obra, pois ele está

\footnotetext{
12 "A malignidade da natureza humana não deve, portanto, chamar-se maldade, se esta palavra se toma em sentido estrito, a saber, como uma disposição de ânimo (princípio subjectivo das máximas) de admitir como móbil o mal enquanto mal na própria máxima (pois ela é diabólica), mas antes perversidade do coração, o qual, por conseqüência, se chama um mau coração" (KANT, p. 43).

${ }^{13}$ Conferir COSTESKI, 2009, p. 120.

${ }^{14}$ Em Pascal, por exemplo, o tédio é perigoso, pois enseja o encontro com os elementos constitutivos inconvenientes da natureza humana, os quais se busca evitar pela via dos divertimentos (1973, p. 79).

${ }^{15}$ Conferir WEIL, 2012, p. 500.
} 
imediatamente em sua obra, ele se torna com a pura atividade negadora da razão a própria negatividade mediada em si (WEIL, 2012, p. 501).

De acordo com Caillois, o discurso filosófico é capaz de constituir em conceito a violência pura quando se depara com seu evento (1984, p. 214). Não obstante, por representar uma fratura irreparável no discurso da razão, ela ocasiona também estupor e assombro do ponto de vista de uma lógica da filosofia. Esse encontro escandaloso faz com que a razão se dê conta de que não existe concreta e historicamente sem aquilo que é seu duplo, sua caricatura que a segue como uma sombra: a violência pura. Dela se diz "pura" por representar o absurdo da opção pelo contra-senso ${ }^{16}$.

É importante ainda salientar que tanto a rejeição quanto a completa recusa da razão perpetradas pelo diabólico não equivalem a um estado de barbarismo tosco e caótico. O recurso e a pressuposição de uma estrutura estatal que a violência total requer já indicam que não se trata de uma oposição por puro ato ao raciocínio e a inteligência ${ }^{17}$, mas de uma instrumentalização da razão a serviço de um agir violento. Weil não nos deixa perder de vista que, no tocante a realização incessante que é a violência pura, o discurso razoável é usado, a guisa de ferramenta ou instrumentalizado como um animal doméstico, sem que, no entanto, aquele que emprega o artifício se torne ele próprio aquilo de que se serve (2012, p. 496).

A recusa da razão, portanto, pode ocorrer segundo formas distintas, e em níveis que são equivalentes (SOARES, 1998, p. 26). Convêm ainda fazer notar no que concerne a categoria da obra que a experiência da violência conceitualizada pelos discursos filosóficos por meio do empreendimento de uma lógica da filosofia diz respeito a violência pela violência, embora englobe também outras de suas formas, como aquelas que dizem respeito aos campos da natureza e do passional ${ }^{18}$. Finalmente, esse debruçar-se sobre a compreensão que os variados discursos filosóficos executam tomando o mal como violência se faz evidente depois que o itinerário da razão sofre sua fratura irreparável.

\section{O Desafio do Mal para a Compreensão:}

No pensamento weiliano o tema do mal não é abordado no contexto de uma teodicéia. Na categoria da discussão e mesmo na categoria de Deus, por exemplo, o mal não é concebido como uma força maligna que constrange o homem para o caminho do erro. Escrevendo após Auschwitz,

\footnotetext{
${ }^{16}$ Conferir CAILLOIS, 1984, p. 214.

${ }^{17}$ Nesse sentido, é digno de nota apontar o papel da retomada do discurso da categoria da inteligência pela obra - portanto, a obra da inteligência -, levando-se em conta que a interpretação que a própria inteligência engendra não também é criação (DEPADTEJCHENBAUM, 1984, p. 175- 179).

${ }^{18}$ Conferir CAILLOIS, 1984, p. 214.
} 
Weil se situa no momento posterior de um itinerário que tem como um marco o grande sismo de Lisboa: "A natureza não tem significado; seus eventos não são sinais. Já não esperamos que os objetos naturais sejam objetos de julgamento moral, nem sequer que os reflitam ou com eles se harmonizem" (NEIMAN, 2003, p. 294). Os males naturais são entendidos como tais apenas para as vontades morais que se encontram em luta com a natureza exterior; os objetos naturais não são maus em si mesmos, de modo que fica claro que a vontade má não pode ser imputada a acontecimentos como terremotos ${ }^{19}$. Isso, entretanto, não torna o evento do mal uma dificuldade anacrônica ou um problema hipostasiado. Enquanto negação do sentido, o mal se apresenta como um problema para a própria significação das ações e do existir do homem no mundo. E isso se torna particularmente claro quando tomamos como exemplo o caso da violência total:

Enviar crianças para lutar pela Grã-Bretanha na lama de Flandres sem perceber o poder das armas postas em suas mãos pode ser chamado de total negligência criminosa. Reunir crianças de todos os cantos da Europa e mandá-las para câmaras de gás na Polônia não pode. O número de judeus enfiados em trens para transporte de gado foi até calculado com exatidão; a SS não desejava pagar à Reichsbahn mais do que as tarifas econômicas de grupos pelo custo de transportar pessoas para serem assassinadas. É difícil imaginar um ato mais intencional no nível estrutural (NEIMAN, 2003, p. 297).

Entender o mal como violência propicia que a reflexão filosófica atinja tanto eventos que escandalizam a razão quanto aqueles que se constituem como uma negativa para os sentidos de certos mundo estabelecidos bem como que se trate também das passagens de certos mundos de sentido para outros. Dito isso, uma das maneiras segundo as quais é possível realizar o enfrentamento da violência na Lógica da Filosofia visando uma compreensão é recorrendo ao modo como os diversos discursos filosóficos depreendem o mal. Como a obra mais célebre de Weil é por sua vez uma tentativa de apreender essa diversidade de discursos, o tratamento filosófico da violência é um esforço de compreender a compreensão elaborada por cada pensamento quando estes são colocados diante daquilo que é em si mesmo incompreensível. Sendo mais preciso, já que a violência é a própria negação do sentido e do essencial para o discurso - e sendo por isso, pura incompreensão - trata-se na Lógica da Filosofia de compreender o caráter incompreensível do mal enquanto violência. Tendo por guia a noção de que o entendimento do outro da razão se dá precisamente por via daquilo que tal alteridade busca negar, essa empreitada se realiza por meio de um artifício, a metagoge: empresta-se a violência o

${ }^{19}$ Conferir NEIMAN, 2003, p. 297. 
uso de um discurso que ela não possui ${ }^{20}$. A partir daí torna-se claro entender que, tomado enquanto negação do sentido, o mal na Lógica da Filosofia aparece nas categorias trabalhadas como a negação daquilo que constitui o essencial para o mundo dos homens situados naquela atitude; daquilo que os escandaliza, mas isso apenas do ponto de vista da razão.

\section{Referências bibliográficas}

CAILLOIS, Roland. La violence pure est-elle démoniaque? In: Actualité d'Eric Weil, Chantilly, 21-22 maio 1984. Paris, 1984. p. 213-222.

CAMARGO, Sérgio de Siqueira. Filosofia e política em Weil: um estudo sobre a idéia de cidadania na filosofia política de Éric Weil. Paulo: Edições Loyola, 2014.

CANIVEZ, Patrice. Weil. Paris: Sociéte d'édition les Belles Lettres, 1999. COSTESKI, Evanildo. Atitude, violência e Estado mundial democrático: sobre a filosofia de Eric Weil. São Leopoldo: Unisinos; Fortaleza: UFC, 2009.

DEPADT-EJCHENBAUM, Mireille. "L'intelligence ou le contra-sens du sens", in Actualité d'Eric Weil, Chantilly, 21-22 mai 1982, Paris 1984, 5376.

KANT, Immanuel. A religião nos limites da simples razão. Lisboa: Edições 70, 2008.

NEIMAN, Susan. $O$ mal no pensamento moderno: uma história alternativa da filosofia. Rio de Janeiro: DIFEL, 2003.

PASCAL, Blaise. Pensamentos. São Paulo: Abril Cultural, 1973.

PERINE, Marcelo. Filosofia e violência. São Paulo: Edições Loyola, 1987.

. Eric Weil e a compreensão do nosso tempo. São Paulo, 2004.

SOARES, Marly Carvalho. O filósofo e o político segundo Eric Weil. São Paulo: Loyola, 1998.

WEIL, Eric. Lógica da Filosofia. São Paulo: É Realizações, 2012. - Philosophie et Réalité. Derniers Essais et Conférences. Paris, Beauchesne Editeur ,1982.

\footnotetext{
${ }^{20}$ Sobre a utilização desse recurso metodológico como forma de compreensão da violência em Weil conferir PERINE, 1987, p. 176.
} 